\title{
Maternal education gradients in early life height: $A$ comparative study of eight Latin American countries
}

\section{Alejandra Abufhele ( $\nabla$ alejandra.abufhele@uc.cl)}

Pontificia Universidad Católica de Chile: Pontificia Universidad Catolica de Chile

https://orcid.org/0000-0001-8476-4988

Kasim Allel

University College London

Marigen Narea

Pontifical Catholic University of Chile: Pontificia Universidad Catolica de Chile

Jane Waldfogel

Columbia University

Research

Keywords: maternal education, stunting, HAZ

Posted Date: March 1st, 2021

DOl: https://doi.org/10.21203/rs.3.rs-237177/v1

License: (9) This work is licensed under a Creative Commons Attribution 4.0 International License.

Read Full License 


\section{Abstract \\ Background}

More than $20 \%$ of the children around the world were stunted in 2018 . The situation is not any better in Latin American countries, even though stunting prevalence has been declining since 2000. Stunting has adverse consequences on children: severe short- and long-term health and functional effects, poor cognition and educational performance, low adult wages, and productivity loss.

\section{Methods}

This study compares maternal education gradients in height-for-age z-scores (HAZs) and stunting prevalence in children between two and four years of age from eight different Latin American countries: Chile, Uruguay, Costa Rica, Paraguay, Mexico, El Salvador, Nicaragua, and Peru.

\section{Results}

Results show that the prevalence of stunting varies widely across Latin American countries. Having a mother with tertiary education increases HAZs in every country (except Paraguay), compared to having a mother with primary education or less. In some countries, there is also a difference in HAZs associated with secondary versus primary maternal education. With regard to stunting, maternal education is a crucial determinant to decrease the odds of being stunted in early years in countries with the highest stunting prevalence $(\approx 20 \%)$; however, this is not the case for countries where the prevalence is low $(<$ $5 \%$.

\section{Conclusions}

We found that maternal education is associated with height and stunting in preschool-aged children in our sampled Latin American countries. The association's magnitude is higher for LMICs than for countries with a higher income per capita in the zone (i.e., Chile and Uruguay). These results suggest that future policies aiming to increase maternal education will improve children's height-for-age and decrease their risk of stunting.

\section{Introduction}

Favorable physical growth, particularly in the early years of life, has been shown to have an extensive impact on population health, enhancing cognitive and socioemotional skills, allowing people to live longer in a healthy condition (Dewey \& Begum, 2011; Grantham-McGregor et al., 2007; Guerrant et al., 2013; Martorell, 1999; Reynolds et al., 2017; Stevens et al., 2012; Walker et al., 2007). According to the latest report of the World Health Organization (WHO), childhood nutrition is essential for proper growth 
(WHO, 2020). The worldwide prevalence of stunting in children under 5 years of age, defined as being two standard deviations (SDs) below the WHO child growth standard median, has decreased by $12 \%$ in the last 20 years (De Onis et al., 2019). However, the trend remains dissimilar in low- and middle-income countries (LMICs), where poverty, sanitation, and hygiene levels are still a social concern of population health (Perkins et al., 2017; Prendergast \& Humphrey, 2014).

Recent studies have depicted that inappropriate child growth-stunting-results from a complex interaction among household, environmental, socioeconomic, and cultural influences (Stewart et al., 2013). Consequently, it might have severe short- and long-term health and functional consequences, including poor cognition and educational performance, low adult wages, and productivity loss (De Onis \& Branca, 2016). Studies from LMICs from Latin America have shown that children's cognitive, physical, communicational, and socio-emotional development is shaped by the family's socioeconomic status (SES) (Araujo et al., 2015; Dekker et al., 2010; Lee et al., 2012; Schady et al., 2015; Segretin et al., 2016). Diversely from high-income countries (HICs), in LMICs this relationship can be derived from poor nutrition and lack of access to clean water, inadequate psychosocial stimulation, and the presence of repetitive infections causing impaired development in children under the age of 5 years living in low SES environments (Bradley \& Corwyn, 2002; Ngure et al., 2014). Moreover, the high inequality in stunting levels between and within Latin America's LMICs has led to pay special attention to family's socioeconomic background to understand, and therefore tackle, the existing disparities while improving children's health.

The following study compares height-for-age z-scores (HAZs) and stunting prevalence in children between 2 and 4 years of age from eight different Latin American countries: Chile, Uruguay, Costa Rica, Paraguay, Mexico, El Salvador, Nicaragua, and Peru, focusing on maternal educational gradients. The paper aims to shed light on how socioeconomic and family background could enhance children's development from a comparative perspective. This research provides a cross-country comparison in the child, maternal, and household determinants of height-for-age and stunting prevalence by comparing the maternal education component's importance in the association with height-for-age and stunting.

\section{Context}

According to the 2018 Global Nutrition Report, the percentage of children under the age of 5 years who were stunted in Latin American countries was 9.6\% (Fanzo et al., 2018). Furthermore, chronic undernutrition in Latin America and the Caribbean can vary widely; some countries face medium (10$20 \%)$, high $(20-30 \%)$, or very high stunting rates (>30\%) (Keeley et al., 2019$)$.

The vast disparities within the region are represented in our sample of Latin American countries. Table 1 shows the mean and SD of the HAZ index by country (appendix, Figure A1), whereas Figure 1 shows the prevalence of stunted children by country (appendix, Figure A2). The prevalence of stunted children varies widely across countries. Chile and Uruguay have the lowest percentage of stunted children (2.8 and 3.8\%, respectively), while other countries range between 10 and 15\% (Costa Rica, Paraguay, Mexico, and El Salvador) and the most extreme countries are bordering 20\% (Nicaragua and Peru). 
In terms of demographic indicators, Table 2 shows economic and public health parameters for each country closer to the year of our infant data (2013) to understand the demographic and economic contexts of the different countries. Table 2 shows that countries with higher health expenditures have lower stunting prevalence. Yet, other indicators, such as infant mortality rate, are also aligned to the prior. The more investment the government puts into health, the better the outcomes for children.

The disparities in HAZs and stunting prevalence have been explained by different factors (del Pilar FloresQuispe et al., 2019; Frongillo et al., 1997), but we want to pay close attention to a specific aspect: maternal educational gradients and their role in explaining the HAZs and stunting prevalence across countries. Figure 2 shows maternal education by country, and Figure 3 displays stunted children's prevalence by maternal educational and country. Secondary education is the most frequent maternal education level in most countries, while primary education remains the most prevalent level in countries like Costa Rica and Nicaragua. When looking at both maternal education level and stunting prevalence, a negative correlation is seen in every country (e.g., if education increases, stunting prevalence decreases).

Therefore, these figures raise new questions about how relevant maternal education is in determining HAZs and stunting prevalence in children under the age of 5 years. This paper explores how maternal education gradients affect HAZs and stunting prevalence and how these gradients differ by nation.

\section{Data And Methods}

Data

This paper uses the "Latin American - Center for Advanced Studies on Educational Justice" data project (LATAM-CJE), which is a multi-sectoral effort aiming to merge early childhood datasets from different countries in Latin America. The main goal of the project is to generate regionally comparative research on child development outcomes. Thus far, the project has included eight Latin American countries. Data were extracted from four surveys. First, early childhood data from Mexico and El Salvador were obtained from the Multiple Indicator Cluster Surveys (MICS), an international project carried out in LMICs by UNICEF that collects information about children and their households every five years (UNICEF, 2016). Second, data from Costa Rica, Nicaragua, Paraguay, and Peru were accessed through the Regional Project on Child Development Indicators (PRIDI), which was led by the Inter-American Development Bank (IDB) in 2013 (Verdisco et al., 2016). They measured child development indicators in children between 24 and 59 months of age. Third and fourth, data from Chile and Uruguay were extracted from their countryspecific early childhood longitudinal studies: the Longitudinal Survey on Early Childhood Development (ELPI), and the Nutrition, Child Development, and Health Survey (ENDIS), respectively (Chilean Ministry of Social Development and Family, 2020; Uruguayan Ministry of Social Development, 2020). 
We restricted our sample to children aged between 2 and 4 years (24 to 48 months old) for the present analysis. The chosen range represents a crucial developmental stage for the height-for-age marker. Full sample sizes and analytical sample sizes are shown in Appendix Table 1.

\section{Measures}

Two dependent variables were used in the models: HAZs and stunting prevalence. Height was objectively measured in each survey using a measuring tape from the floor to the children to get their full size in centimeters. For our analysis, we standardized height-for-age based on WHO standards for age and sex. Stunting is defined as a HAZ of less than or equal to two height-for-age standard deviations (SDs) from the WHO Child Growth Standards (WHO, 2006).

The main independent variable is maternal education level, which we divided into three categories: primary or less, secondary, and tertiary education level. The exact definition of each of these categories varies depending on the country. Primary education is defined as six years of formal schooling in all countries[1]. In terms of secondary level, Chile, El Salvador, Mexico, Paraguay, and Uruguay have six years of secondary school, while Costa Rica, Nicaragua, and Peru have five years of secondary school. Any years of education after secondary education were categorized as tertiary education.

Independent variables incorporated as covariates included characteristics of the mother, child, and household. Mother characteristics were age (in years) and ethnicity (which indicates whether the mother spoke indigenous language). Child characteristics included age in months, gender, and whether they were breastfed. Household characteristics contained three different variables: the number of people living in the household, the total number of additional children living at home, and wealth or income terciles (computed based on different scales and measures depending on the survey). Finally, to capture parenting style, we added two childhood stimulation variables: whether the parents stimulated their child by singing them a song and whether they regularly told their child stories (both presented as dichotomous variables). Table 3 depicts the descriptive statistics of our sample by country. The table shows that levels of stunting and levels of maternal education differ by country (also shown in Fig. 1 and Fig. 2). In terms of maternal age, the samples are quite similar, with means from 27.5 years in Costa Rica through 32.5 years in El Salvador. Ethnicity and rurality are characteristics that vary greatly between countries: ethnicity ranges from $0.7 \%$ in Costa Rica through $37.1 \%$ in Paraguay, and rurality ranges from $10.6 \%$ in Chile through $43 \%$ in El Salvador. Children characteristics are quite similar across countries: age in months, sex, and if they were breastfed.

To understand each national context, we compare our sample of mothers, whose children were 2 to 4 years old, with the standard socio-economic survey of each country to contrast our main independent variable: maternal education level. The results from this exercise are shown in appendix, section B. Our sampled mothers are in general much more educated for all countries than in the whole population. The main explanation behind this is that this is a relatively young section of the population-it represents a younger cohort born mainly after primary and secondary education became universal in these countries. 
Thus, we should bear in mind that we work with a non-random sample of a much more educated population than what is observed in the whole population.

\section{Methods}

In the first set of analyses, we run linear regression models for the HAZ separately by country, as indicated in equation (1). The dependent variable corresponds to the height-for-age for the child $i$, and the main independent variable are dummies for maternal educational level (), where the first categoryprimary or less-is omitted. Therefore, an interpretation of the coefficients is made in comparison to this category. is a matrix of "j" observed child characteristics, including mother and household characteristics, and is the error term.

\section{See formulas 1 and 2 in the supplementary files.}

[1] Paraguay adopted a reform establishing 9 years for primary education, but we used 6 years for primary and 6 years for secondary according to the international equivalent educational standards of the United Nations Educational, Scientific, and Cultural Organization (UNESCO; UNESCO, 2013, 2015).

\section{Results}

Results from the first set of analyses indicate the importance of maternal education for HAZs among children between 24 and 48 months. Figure 4 shows the coefficients estimated for maternal secondary and tertiary education graphically by country compared to primary or less. Table 4 displays the coefficient estimates by country for the full model. For almost all countries, children of mothers with tertiary education had higher HAZs, compared to children of mothers with primary education or less. The exception is Paraguay, where there is no clear association between maternal educational level and HAZs. The maternal educational gradient varies by country: the smallest tertiary-primary gap was estimated for Chile at 0.2 SDs, i.e., children of mothers with tertiary education in Chile were 0.2 SDs taller than were children of mothers with primary education. Countries like Uruguay, Mexico, El Salvador, and Peru had a gradient ranging between 0.3 and 0.4 SDs. In contrast, countries like Costa Rica and Nicaragua show a maternal educational gradient from at least half a SD in height for age. The differences are less consistent when comparing children from mothers with secondary education versus primary or less. There is only a difference in HAZs in some countries between children of mothers with secondary and primary education: Uruguay, Mexico, El Salvador, and Peru.

With regard to other covariates, mother's age is relevant to explain HAZs in children under 5 years, but only in some countries: Chile, Mexico, El Salvador, and Peru. Nonetheless, the magnitude of the coefficient is small. Ethnicity was a relevant predictor in countries like Mexico, El Salvador, and Peru. The coefficients were 0.4 SDs for Mexico and El Salvador and 0.8 for Peru, which was of a higher relevance than the maternal educational gradient. Similarly, household wealth terciles were significant predictors of HAZs for 
all countries. The gradient in HAZs between belonging to the wealthier tercile and the poorer tercile varies between countries, being more important for countries like Paraguay (0.7 SDs), El Salvador (0.6 SDs), and Peru (0.5 SDs) and less important for countries like Chile (0.2 SDs) and Uruguay, where the coefficient did not present any meaningful variation.

Table 5 and Figure 5 depict the results for the models for stunting. Maternal education level is a crucial predictor for countries with a higher current stunting prevalence. Countries like Chile and Uruguay, where the prevalence is less than $4 \%$, exhibited no differences in their respective stunting prevalence by mother's primary, secondary, or tertiary education level. Costa Rica, which has a prevalence of stunted children of $9 \%$, did not display a maternal education gradient either. Notwithstanding, Paraguay (12\% stunting prevalence) showed that mothers with tertiary education have almost a $50 \%$ lesser chance of having a stunted child than mothers with primary education level or less. The gradient is well observed in Mexico, where the odds for children of mothers with secondary education are 35\% lower than they were for children of mothers with primary education or less. Meanwhile, having tertiary education increases these odds in about $50 \%$. The maternal educational gradient is even more exacerbated in countries like El Salvador, Nicaragua, and Peru, where the stunting prevalence is the highest of our sampled countries $(\approx 15 \%)$. Lower odds of stunting prevalence were seen if the mother had a higher education level. With regard to other covariates, an important finding is that with Nicaragua's exception, wealth terciles are vital determinants in predicting stunting prevalence, being even stronger than maternal educational gradients in some of our sampled countries.

Finally, we did an exploratory analysis by looking at the differences by child's gender and urban/rural residence. Even though for some countries sample sizes are small, Tables C1 and C2 in the appendix demonstrate these results. For boys, there is no clear pattern for all countries, but for girls, we see secondary and tertiary education being an important determinant of HAZs in those countries with a higher prevalence of stunting: Mexico, El Salvador, Nicaragua, and Peru. We saw no clear pattern for rurality, and the most important significant finding was found for Peru, where we observed a difference between urban and rural residency. For urban residency, the maternal educational gradient is important at the secondary and tertiary educational levels; however, maternal educational level was not a clear driver of children's HAZs in the rural zone.

\section{Conclusions}

This research article examined the association between height-for-age and stunting and maternal educational level among children between 2 and 4 years old from eight different Latin American countries. Our results evidence that children whose mothers have tertiary education had an increased HAZ in every country-except for Paraguay-compared to children whose mothers have primary education or less. In addition, maternal education was a crucial determinant in decreasing the odds of stunting in countries with a high stunting prevalence (Mexico, El Salvador, Nicaragua, and Peru), but not 
in countries where the prevalence of stunting was low (Chile, Uruguay, Costa Rica, and Paraguay). We view these maternal educational gradients as capturing cultural capital rather than economic resources, as we control for wealth terciles.

Our results are consistent with the previous literature on socioeconomic characteristics and how they affect stunting prevalence in the early years in LMICs (Black et al., 2013; Lu et al., 2016). For Latin American countries, studies have found that children with illiterate primary caregivers were 5 times more likely to be stunted compared with their counterparts with literate primary caregivers in Guatemala (Sereebutra et al., 2006), and maternal stature, low body mass index (BMI), low education, and poverty were also predictors of stunting in Uruguay (Bove et al., 2012). For Colombia, child stunting is associated with lower socioeconomic and maternal nutritional statuses (Dekker et al., 2010). To our knowledge, this is the first study to examine the influence of maternal education on HAZs and stunting across a range of Latin American countries.

This paper has some limitations. First, we do not have information on nutritional aspects for each country; this could explain some of the heterogeneous results we are finding across countries. Second, as with many comparative papers, we have to limit the number of controls in the estimations to those available in each survey. This may limit the analysis by introducing a potential omitted variable bias. Third, even though our analyses used several Latin American countries, our results do not necessarily represent other countries across the zone, because of either missing studies or data availability. Fourth, we lacked data on other environmental characteristics affecting early height and stunting, such as a lack of solid waste disposal, a lack of sanitation, solid fuels in the household, and dirt floor and material deprivation, although we did use socioeconomic measures to proxy for these differences.

Despite these limitations, this study advances the literature on early childhood growth in Latin American countries from a comparative perspective by using a combination of national surveys. We harmonized and merged the data on early childhood stunting and sociodemographic variables, which no study has done before, resulting in a study of a considerable sample size. A particular strength is the standardization of the anthropometric measures-HAZ and stunting-allowing a reasonable degree of comparability between estimates. Finally, we use the most recent surveys from countries, most from 2012-2013.

In conclusion, we found that maternal education is associated with height and stunting in preschool-aged children in our sampled Latin American countries. The association's magnitude is higher for LMICs than for countries with a higher income per capita in the zone (i.e., Chile and Uruguay). This could be explained in part because formal education may equip parents to apply successfully knowledge about health, sanitation, and responsive interaction when caring for their children (Pamuk et al., 2011), which could prevent them from stunting in the context of low or moderate income.

These findings support the importance of improving maternal education as a way of enhancing children's nutritional and environmental conditions during the early ages to ensure proper linear growth throughout childhood. Another approach would be to provide additional supports to families with less educated 
mothers. Successful interventions are often implemented as multi-sectoral packages anchored in nurturing care and include parenting support, preschool participation, and responsive care (Britto et al., 2016). Interventions should aim at lessening the difficulties imposed by the environmental disruptors of child development. This is part of the Sustainable Development Goals (SDGs) for 2030, aiming to tackle stunting to ensure every child can reach their potential over their life course (Richter et al., 2017).

\section{Declarations}

Ethics approval and consent to participate: not applicable, data was public.

Consent for publication: not applicable, data was public.

Availability of data and material: the datasets analyzed during the current study are available in the web page for each survey.

https://www.iadb.org/en/sector/education/pridi/home

https://mics.unicef.org/surveys

https://www.gub.uy/ministerio-desarrollo-social/endis

http://observatorio.ministeriodesarrollosocial.gob.cl/elpi-tercera-ronda

Competing interests: The authors declare that they have no competing interests.

Funding: ANID PIA CIE 160007

Author contributions: Conceptualization AA, KA, MN, JW; Methodology AA, KA, Formal Analysis AA, KA; Writing $A A$, Review and Editing $A A, K A, M N$, JW. All authors have read and approved the final version of the manuscript.

Acknowledgements: Millennium Nucleus for the Study of the Life Course and Vulnerability (MLIV), Santiago, Chile.

\section{References}

Araujo, M. C., Ardanaz, M., Armendáriz, E., Behrman, J. R., Berlinski, S., Cristia, J. P., Flabbi, L., Hincaple, D., Jalmovich, A., Kagan, S. L., Lopez Boo, F., Perez Exposito, A., \& Schady, N. (2015). The early years: Child well-being and the role of public policy. IDB Publications (Books).

Black, R. E., Victora, C. G., Walker, S. P., Bhutta, Z. A., Christian, P., De Onis, M., Ezzati, M., GranthamMcGregor, S., Katz, J., Martorell, R., Uauy, R., \& Maternal and Child Nutrition Study Group. (2013). Maternal and child undernutrition and overweight in low-income and middle-income countries. The Lancet, 382, 427-451. 
Bove, I., Miranda, T., Campoy, C., Uauy, R., \& Napol, M. (2012). Stunting, overweight and child development impairment go hand in hand as key problems of early infancy: Uruguayan case. Early Human Development, 88(9), 747-751.

Bradley, R. H., \& Corwyn, R. F. (2002). Socioeconomic status and child development. Annual Review of Psychology, 53, 371-399.

Carvalho, L. (2012). Childhood circumstances and the intergenerational transmission of socioeconomic status. Demography, 49, 913-938.

Chilean Ministry of Social Development and Family. (2020). Longitudinal Survey on Early Childhood Development (ELPI).

De Onis, M., Borghi, E., Arimond, M., Webb, P., Croft, T., Saha, K., De-Regil, L. M., Thuita, F., Heidkamp, R., Krasevec, J., Hayashi, C., \& Flores-Ayala, R. (2019). Prevalence thresholds for wasting, overweight and stunting in children under 5 years. Public Health Nutrition, 22, 175-179.

De Onis, M., \& Branca, F. (2016). Childhood stunting: A global perspective. Maternal \& Child Nutrition, 12, 12-26.

Dekker, L. H., Mora-Plazas, M., Marín, C., Baylin, A., \& Villamor, E. (2010). Stunting associated with poor socioeconomic and maternal nutrition status and respiratory morbidity in Colombian schoolchildren. Food and Nutrition Bulletin, 31, 242-250.

del Pilar Flores-Quispe, M., Restrepo-Méndez, M. C., Maia, M. F. S., Ferreira, L. Z., \& Wehrmeister, F. C. (2019). Trends in socioeconomic inequalities in stunting prevalence in Latin America and the Caribbean countries: Differences between quintiles and deciles. International Journal for Equity in Health, 18, 156.

Dekker, L., Mora-Plazas, M., Marín, C., Baylin, A., \& Villamor, E. (2010). Stunting associated with poor socioeconomic and maternal nutrition status and respiratory morbidity in Colombian schoolchildren. Food and Nutrition Bulletin, 31, 2.

Dewey, K. G., \& Begum, K. (2011). Long-term consequences of stunting in early life. Maternal \& Child Nutrition, 7, 5-18.

Fanzo, J., Hawkes, C., Udomkesmalee, E., Afshin, A., Allemandi, L., Assery, O., Baker, P., Battersby, J., Bhutta, Z., Chen, K., Corvalan, C., Di Cesare, M., Dolan, C., Fonseca, J., Grummer-Strawn, L., Hayashi, C., McArthur, J. Rao, A., Rosenzweig, C., \& Schofield, D. (2018). 2018 Global Nutrition Report: Shining a light to spur action on nutrition.

https://www.who.int/nutrition/globalnutritionreport/2018_Global_Nutrition_Report.pdf?ua=1

Fotso, J. C. (2006). Child health inequities in developing countries: Differences across urban and rural areas. International Journal for Equity in Health, 5(1), 9. 
Freeman, M. C., Garn, J. V., Sclar, G. D., Boisson, S., Medlicott, K., Alexander, K. T., Penakalapati, G., Anderson, D., Mahtani, A. G., Grimes, J. E. T., Rehfuess, E. A., \& Clasen, T. F. (2017). The impact of sanitation on infectious disease and nutritional status: A systematic review and meta-analysis. International Journal of Hygiene and Environmental Health, 220, 928-949.

Frongillo, E. A., Jr., De Onis, M., \& Hanson, K. M. (1997). Socioeconomic and demographic factors are associated with worldwide patterns of stunting and wasting of children. The Journal of Nutrition, 127, 2302-2309.

Grantham-McGregor, S., Cheung, Y. B., Cueto, S., Glewwe, P., Richter, L., Strupp, B., \& International Child Development Steering Group. (2007). Developmental potential in the first 5 years for children in developing countries. The Lancet, 369, 60-70.

Guerrant, R. L., DeBoer, M. D., Moore, S. R., Scharf, R. J., \& Lima, A. A. (2013). The impoverished gut-a triple burden of diarrhoea, stunting and chronic disease. Nature Reviews Gastroenterology \& Hepatology, $10,220$.

Inter-American Development Bank. (2013). Regional Project on Child Development Indicators (PRIDI). https://www.iadb.org/en/sector/education/pridi/home

Keeley, B., Little, C., \& Zuehlke, E. (2019). The state of the world's children 2019: children, food and nutrition-growing well in a changing world. UNICEF.

Lee, J., Houser, R. F., Must, A., de Fulladolsa, P. P., \& Bermudez, O. I. (2012). Socioeconomic disparities and the familial coexistence of child stunting and maternal overweight in Guatemala. Economics \& Human Biology, 10, 232-241.

Lu, C., Black, M. M., \& Richter, L. M. (2016). Risk of poor development in young children in low-income and middle-income countries: An estimation and analysis at the global, regional, and country level. The Lancet Global Health, 4, e916-e922.

Martorell, R. (1999). The nature of child malnutrition and its long-term implications. Food and Nutrition Bulletin, 20, 288-292.

Menon, P., Ruel, M. T., \& Morris, S. S. (2000). Socio-economic differentials in child stunting are consistently larger in urban than in rural areas. Food and Nutrition Bulletin, 21(3), 282-289. https://doi.org/10.1177/156482650002100306

Ngure, F. M., Reid, B. M., Humphrey, J. H., Mbuya, M. N., Pelto, G., \& Stoltzfus, R. J. (2014). Water, sanitation, and hygiene (WASH), environmental enteropathy, nutrition, and early child development: making the links. Annals of the New York Academy of Sciences, 1308, 118-128.

Perkins, J. M., Kim, R., Krishna, A., McGovern, M., Aguayo, V. M., \& Subramanian, S. (2017). Understanding the association between stunting and child development in low-and middle-income countries: Next steps 
for research and intervention. Social Science \& Medicine, 193, 101-109.

Prendergast, A. J., \& Humphrey, J. H. (2014). The stunting syndrome in developing countries. Paediatrics and International Child Health, 34, 250-265.

Pamuk, E., Fuchs, R., \& Lutz, W. (2011). Comparing relative effects of education and economic resources on infant mortality in developing countries. Population and Development Review, 37(4), 637-664. http://www.jstor.org/stable/41762375

Reynolds, S. A., Andersen, C., Behrman, J., Singh, A., Stein, A. D., Benny, L., Crookston, B. T., Cueto, S., Dearden, K., Georgiadis, A., Krutikova, S., \& Fernald, L. C. H. (2017). Disparities in children's vocabulary and height in relation to household wealth and parental schooling: A longitudinal study in four low-and middle-income countries. SSM-Population Health, 3, 767-786.

Richter, L. M., Daelmans, B., Lombardi, J., Heymann, J., Lopez Boo, F., Behrman, J. R., Lu, Chunling, Lucas, J. E., Perez-Escamilla, R., Dua, T., Bhutta, Z. A., Stenberg, K., Gertler, P., Darmstadt, G. L., \& Paper 3 Working Group and the Lancet Early Childhood Development Series Steering Committee. (2017). Investing in the foundation of sustainable development: Pathways to scale up for early childhood development. The Lancet, 389, 103-118.

Schady, N., Behrman, J., Araujo, M.C., Azuero, R., Bernal, R., Bravo, D., Lopez-Boo, F., Macours, K., Marshall, D., Paxson, C., \& Vakis, R. (2015). Wealth gradients in early childhood cognitive development in five Latin American countries. Journal of Human Resources, 50(2), 446-463.

Segretin, M. S., Hermida, M. J., Prats, L. M., Fracchia, C. S., Ruetti, E., \& Lipina, S. J. (2016). Childhood poverty and cognitive development in Latin America in the 21st century. New Directions for Child and Adolescent Development, 2016, 9-29.

Sereebutra, P., Solomons, N., Aliyu, M. H., \& Jolly, P. E. (2006). Sociodemographic and environmental predictors of childhood stunting in rural Guatemala. Nutrition Research, 26(2), 65-70.

Stevens, G. A., Finucane, M. M., Paciorek, C. J., Flaxman, S. R., White, R. A., Donner, A. J., Ezzati, M., \& Nutrition Impact Model Study Group (Child Growth). (2012). Trends in mild, moderate, and severe stunting and underweight, and progress towards MDG 1 in 141 developing countries: A systematic analysis of population representative data. The Lancet, 380, 824-834.

Stewart, C. P., lannotti, L., Dewey, K. G., Michaelsen, K. F., \& Onyango, A. W. (2013). Contextualising complementary feeding in a broader framework for stunting prevention. Maternal \& Child Nutrition, 9, 2745 .

UNESCO. (2013). Clasificación Internacional Normalizada de la Educación (CINE) 2011. https://unesdoc.unesco.org/ark:/48223/pf0000220782_spa 
UNESCO. (2015). International Standard Classification of Education Fields of Education and Training 2013 (ISCED-F 2013): Detailed Field Descriptions of the Institute for Statistics. Montreal, QC: UNESCO Institute for Statistics.

UNICEF (2016). Multiple Indicator Cluster Survey (MICS). http://mics.unicef.org/

Uruguayan Ministry of Social Development. (2020). Nutrition, Child Development and Health Survey (ENDIS).

Verdisco, A., Cueto, S., \& Thompson, J. (2016). Early childhood development: Wealth, the nurturing environment and inequality first results from the pridi database. IDB Working Paper Series.

Vilcins, D., Sly, P. D., \& Jagals, P. (2018). Environmental risk factors associated with child stunting: A systematic review of the literature. Annals of Global Health, 84, 551.

Walker, S. P., Wachs, T. D., Gardner, J. M., Lozoff, B., Wasserman, G. A., Pollitt, E., Carter, J. A., \& International Child Development Steering Group. (2007). Child development: Risk factors for adverse outcomes in developing countries. The Lancet, 369, 145-157.

World Health Organization Nutrition and Food Safety. (2006). WHO child growth standards: Length/height-for-age, weight-for-age, weight-for-length, weight-for-height and body mass index-for-age: methods and development. World Health Organization.

World Health Organization Nutrition and Food Safety. (2020). UNICEF/WHO/The World Bank Group joint child malnutrition estimates: Levels and trends in child malnutrition: Key findings of the 2020 edition. World Health Organization.

\section{Tables}

Table 1: Height-for-Age Z-score (HAZ) by Country

\begin{tabular}{lcc}
\hline & \multicolumn{2}{c}{ HAZ Index WHO } \\
Country & Mean & SD \\
\hline Chile & 0.00 & 1.08 \\
Uruguay & -0.17 & 1.06 \\
\hline Costa Rica & -0.43 & 1.47 \\
\hline Paraguay & -0.47 & 2.12 \\
Mexico & -0.87 & 1.13 \\
El Salvador & -1.00 & 1.09 \\
\hline Nicaragua & -0.91 & 1.28 \\
\hline Peru & -1.04 & 1.45 \\
\hline
\end{tabular}

Notes: Height-for-age z-scores (HAZs) based on WHO Child Growth Standards.

Table 2: Demographic Indicators for Countries Year 2013 


\begin{tabular}{|c|c|c|c|c|c|c|c|c|c|}
\hline & Unit & Chile & Uruguay & $\begin{array}{l}\text { Costa- } \\
\text { Rica }\end{array}$ & Paraguay & Mexico & $\begin{array}{c}\text { El } \\
\text { Salvador }\end{array}$ & Nicaragua & Peru \\
\hline ation & $\begin{array}{c}1,000 \\
\text { inhabitants }\end{array}$ & 17,571 & 3,389 & 4,742 & 6,510 & 118,827 & 6,266 & 6,062 & 29,773 \\
\hline ier & $\begin{array}{l}\text { Constant } \\
2010 \text { US\$ }\end{array}$ & 14,461 & 13,541 & 8,785 & 4,699 & 9,693 & 3,212 & 1.716 & 5.919 \\
\hline $\begin{array}{l}\text { ty } \\
\text { ount } \\
\text { it } \\
\text { tal } \\
\text { ty } \\
\text { \% of } \\
\text { ation) }\end{array}$ & $\%$ & 14.4 & 11.5 & 20.7 & 28.0 & 45.5 & 29.6 & 42.5 & 23.9 \\
\hline cient & Coefficient & 47.3 & 40.5 & 49.3 & 47.9 & 45.4 & 43.4 & 43.9 & 43.9 \\
\hline lity & $\begin{array}{l}\text { Per } 1,000 \\
\text { live births }\end{array}$ & 7 & 8 & 8 & 20 & 14 & 15 & 17 & 14 \\
\hline $\begin{array}{l}\text { nt } \\
\text { l } \\
\text { diture } \\
\text { GDP) }\end{array}$ & $\%$ & 7.44 & 8.82 & 7.68 & 6.97 & 5.81 & 6.97 & 7.33 & 4.92 \\
\hline $\begin{array}{l}\text { stic } \\
\text { al } \\
\text { nment } \\
\text { L } \\
\text { diture } \\
\text { pita }\end{array}$ & $\begin{array}{c}\text { Current } \\
\text { international } \\
\$\end{array}$ & 997.67 & $1,168.63$ & 822.68 & 300.21 & 526.25 & 344.95 & 188.30 & 328.97 \\
\hline
\end{tabular}

Notes: OECD; CELAC; WORLD BANK data 2014-2017.

https://ourworldindata.org/pre-primary-education. http://estadisticas.cepal.org/cepalstat/WEB_CEPALSTAT/perfilesNacionales.asp?idioma=. https://stats.oecd.org.

Table 3: Descriptive Statistics 


\begin{tabular}{lcccccccc}
\hline & \multicolumn{2}{c}{ Chile } & \multicolumn{2}{c}{ Uruguay } & \multicolumn{2}{c}{ Costa Rica } & \multicolumn{2}{c}{ Paraguay } \\
\hline & Mean & SD & Mean & SD & Mean & SD & Mean & SD \\
\hline Height raw & 97.2 & 6.087 & 92.7 & 5.418 & 94.0 & 7.475 & 94.4 & 8.760 \\
\hline HAZ & 0.005 & 1.076 & -0.153 & 1.058 & -0.446 & 1.494 & -0.491 & 1.997 \\
\hline Stunting & $2.8 \%$ & 0.164 & $3.8 \%$ & 0.191 & $9.0 \%$ & 0.286 & $13.1 \%$ & 0.337 \\
\hline Mother's education & & & & & & & & \\
\hline \multicolumn{1}{c}{ Primary or less } & $4.3 \%$ & 0.204 & $20.6 \%$ & 0.405 & $50.9 \%$ & 0.500 & $34.3 \%$ & 0.475 \\
\hline \multicolumn{1}{c}{ Secondary } & $74.5 \%$ & 0.436 & $54.3 \%$ & 0.498 & $37.4 \%$ & 0.484 & $43.5 \%$ & 0.496 \\
\hline \multicolumn{1}{c}{ Tertiary } & $21.1 \%$ & 0.408 & $25.0 \%$ & 0.433 & $11.7 \%$ & 0.321 & $22.2 \%$ & 0.416 \\
\hline Mother's age & 29.7 & 7.005 & 29.5 & 7.021 & 27.5 & 6.207 & 29.4 & 6.895 \\
\hline Mother's ethnicity & $7.8 \%$ & 0.269 & $8.0 \%$ & 0.271 & $0.7 \%$ & 0.082 & $37.1 \%$ & 0.483 \\
\hline Age in months & 38.7 & 6.394 & 33.1 & 5.802 & 36.6 & 7.119 & 37.3 & 6.732 \\
\hline Female & $48.7 \%$ & 0.500 & $52.8 \%$ & 0.499 & $51.1 \%$ & 0.500 & $45.9 \%$ & 0.499 \\
\hline Tercile & & & & & & & & \\
\hline \multicolumn{1}{c}{ Wealth tercile 1 } & $37.7 \%$ & 0.485 & $33.4 \%$ & 0.472 & $37.7 \%$ & 0.485 & $31.9 \%$ & 0.466 \\
\hline \multicolumn{1}{c}{ Wealth tercile 2 } & $30.0 \%$ & 0.458 & $35.3 \%$ & 0.478 & $32.2 \%$ & 0.467 & $35.3 \%$ & 0.478 \\
\hline Wealth tercile 3 & $32.3 \%$ & 0.468 & $31.3 \%$ & 0.464 & $30.2 \%$ & 0.459 & $32.8 \%$ & 0.470 \\
\hline Overcrowding & 4.8 & 1.646 & 4.8 & 1.834 & 4.9 & 2.072 & 5.1 & 1.877 \\
\hline Number of other children in HH & 0.9 & 0.929 & 1.2 & 1.273 & 1.0 & 0.997 & 1.0 & 1.027 \\
\hline Rural & $10.6 \%$ & 0.308 & & & $19.0 \%$ & 0.393 & $32.2 \%$ & 0.467 \\
\hline Breastfed & $95.4 \%$ & 0.209 & $97.0 \%$ & 0.169 & $88.3 \%$ & 0.321 & $94.6 \%$ & 0.227 \\
\hline Sang a song & $92.0 \%$ & 0.272 & $89.8 \%$ & 0.303 & $76.3 \%$ & 0.426 & $72.3 \%$ & 0.448 \\
\hline Told a story & $79.3 \%$ & 0.405 & $81.6 \%$ & 0.387 & $56.0 \%$ & 0.497 & $46.2 \%$ & 0.499 \\
\hline Number of observations & 4.640 & & 1.454 & & 746 & & 734 & \\
\hline
\end{tabular}

\begin{tabular}{|c|c|c|c|c|c|c|c|c|}
\hline & \multicolumn{2}{|c|}{ Mexico } & \multicolumn{2}{|c|}{ El Salvador } & \multicolumn{2}{|c|}{ Nicaragua } & \multicolumn{2}{|c|}{ Peru } \\
\hline & Mean & $\mathrm{SD}$ & Mean & $\mathrm{SD}$ & Mean & $\mathrm{SD}$ & Mean & SD \\
\hline Height raw & 91.8 & 6.382 & 91.7 & 6.322 & 92.2 & 6.231 & 91.5 & 6.983 \\
\hline HAZ & -0.872 & 1.133 & -1.001 & 1.094 & -0.906 & 1.285 & -1.047 & 1.447 \\
\hline Stunting & $14.5 \%$ & 0.352 & $16.2 \%$ & 0.369 & $19.5 \%$ & 0.397 & $23.0 \%$ & 0.421 \\
\hline \multicolumn{9}{|l|}{ Mother's education } \\
\hline Primary or less & $24.6 \%$ & 0.431 & $40.4 \%$ & 0.491 & $47.5 \%$ & 0.500 & $24.9 \%$ & 0.433 \\
\hline Secondary & $63.6 \%$ & 0.481 & $49.0 \%$ & 0.500 & $37.8 \%$ & 0.485 & $50.3 \%$ & 0.500 \\
\hline Tertiary & $11.8 \%$ & 0.322 & $10.6 \%$ & 0.308 & $14.7 \%$ & 0.354 & $24.8 \%$ & 0.432 \\
\hline Mother's age & 29.1 & 7.778 & 32.5 & 10.092 & 27.5 & 6.505 & 29.5 & 6.607 \\
\hline Mother's ethnicity & $11.1 \%$ & 0.314 & $0.9 \%$ & 0.092 & $19.6 \%$ & 0.397 & $6.7 \%$ & 0.249 \\
\hline Age in months & 35.7 & 7.318 & 36.2 & 7.529 & 36.5 & 6.851 & 36.1 & 6.998 \\
\hline Female & $48.6 \%$ & 0.500 & $47.7 \%$ & 0.500 & $50.9 \%$ & 0.500 & $47.6 \%$ & 0.500 \\
\hline \multicolumn{9}{|l|}{ Tercile } \\
\hline Wealth tercile 1 & $33.9 \%$ & 0.473 & $34.3 \%$ & 0.475 & $32.4 \%$ & 0.468 & $32.8 \%$ & 0.470 \\
\hline Wealth tercile 2 & $32.3 \%$ & 0.468 & $30.2 \%$ & 0.459 & $34.0 \%$ & 0.474 & $34.7 \%$ & 0.476 \\
\hline Wealth tercile 3 & $33.8 \%$ & 0.473 & $35.5 \%$ & 0.479 & $33.6 \%$ & 0.473 & $32.6 \%$ & 0.469 \\
\hline Overcrowding & 5.1 & 1.910 & 5.1 & 2.021 & 5.6 & 2.345 & 4.7 & 1.695 \\
\hline
\end{tabular}




\begin{tabular}{lcccccccc} 
Number of other children in $\mathrm{HH}$ & 1.6 & 1.431 & 1.3 & 1.308 & 1.1 & 1.137 & 1.0 & 1.237 \\
\cline { 2 - 8 } Rural & $37.1 \%$ & 0.483 & $43.0 \%$ & 0.495 & $39.4 \%$ & 0.489 & $31.8 \%$ & 0.466 \\
\hline Breastfed & $90.9 \%$ & 0.288 & $95.0 \%$ & 0.218 & $98.5 \%$ & 0.122 & $96.4 \%$ & 0.186 \\
\hline Sang a song & $34.0 \%$ & 0.474 & $29.4 \%$ & 0.456 & $68.3 \%$ & 0.466 & $69.6 \%$ & 0.460 \\
\hline Told a story & $27.0 \%$ & 0.444 & $17.9 \%$ & 0.384 & $37.6 \%$ & 0.485 & $56.3 \%$ & 0.496 \\
\hline Number of observations & 3.428 & & 3.176 & & 994 & & 1.486 & \\
\hline
\end{tabular}

Notes: HAZ stands for Height-for-age (z-score)

Table 4: Linear Regression Model Height-for-Age by Country 
Chile Uruguay $\begin{gathered}\text { Costa } \\ \text { Rica }\end{gathered}$ Paraguay Mexico $\quad$ Salvador Nicaragua $\quad$ Peru

sondary (ref.

\begin{tabular}{lcccccccc} 
mary) & 0.075 & $0.155^{*}$ & 0.152 & -0.138 & $0.228^{* * *}$ & $0.153^{* * *}$ & 0.142 & $0.237^{* *}$ \\
\hline tiary (ref. & $(0.083)$ & $(0.079)$ & $(0.115)$ & $(0.206)$ & $(0.046)$ & $(0.043)$ & $(0.095)$ & $(0.097)$ \\
mary) & & & & & & & & \\
& $0.157^{*}$ & $0.258^{* *}$ & $0.500^{* * *}$ & 0.205 & $0.250^{* * *}$ & $0.254^{* * *}$ & $0.559^{* * *}$ & $0.402^{* * *}$ \\
ther's age & $(0.089)$ & $(0.102)$ & $(0.166)$ & $(0.205)$ & $(0.067)$ & $(0.082)$ & $(0.133)$ & $(0.122)$ \\
\hline & $0.009^{* * *}$ & 0.003 & -0.000 & 0.010 & $0.006^{* *}$ & $0.008^{* * *}$ & $0.015^{* *}$ & 0.001 \\
\hline
\end{tabular}

ther's ethnicity

f. no

$\begin{array}{lcccccccc}\text { igenous }) & 0.060 & 0.032 & 0.396 & -0.017 & -0.471^{* * *} & -0.406^{*} & -0.010 & -0.858^{* * *} \\ & (0.058) & (0.099) & (0.589) & (0.198) & (0.062) & (0.238) & (0.108) & (0.167)\end{array}$

ld's age in

nths

$\begin{array}{cccccccc}0.003 & -0.010^{* *} & 0.009 & -0.008 & -0.003 & -0.003 & -0.018^{* * *} & -0.000 \\ (0.002) & (0.005) & (0.009) & (0.012) & (0.003) & (0.003) & (0.006) & (0.005)\end{array}$

ld's sex (ref.

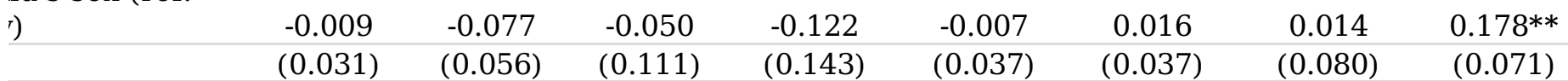

\begin{tabular}{lcccccccc}
\hline alth terciles 2 & & & & & & & & \\
f. first tercile) & $0.114^{* * *}$ & $0.160^{* *}$ & 0.017 & 0.292 & $0.289^{* * *}$ & $0.352^{* * *}$ & $0.264^{* * *}$ & 0.151 \\
& $(0.040)$ & $(0.070)$ & $(0.146)$ & $(0.219)$ & $(0.050)$ & $(0.047)$ & $(0.099)$ & $(0.102)$
\end{tabular}

\begin{tabular}{lllllllll}
\hline alth terciles 3 & & & & & & & \\
f. first tercile) & $0.189 * * *$ & 0.076 & $0.335^{* *}$ & $0.709 * * *$ & $0.411 * * *$ & $0.573^{* * *}$ & $0.395^{* * *}$ & $0.487 * * *$
\end{tabular}

$\begin{array}{lllllllll}\text { f. first tercile } & (0.041) & (0.083) & (0.136) & (0.262) & (0.056) & (0.056) & (0.115) & (0.121)\end{array}$

mber of people

lousehold

$\begin{array}{cccccccc}0.008 & -0.017 & 0.004 & 0.055 & 0.006 & 0.006 & -0.019 & 0.039^{*} \\ (0.013) & (0.027) & (0.036) & (0.046) & (0.013) & (0.012) & (0.023) & (0.024)\end{array}$

mber of other

ldren in

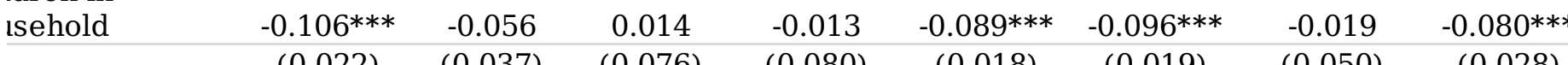

astfed (ref. no

\begin{tabular}{lcccccc} 
astfed) & -0.041 & 0.064 & 0.258 & 0.473 & -0.064 & $0.803^{* * *}$ \\
& $(0.073)$ & $(0.177)$ & $(0.208)$ & $(0.446)$ & $(0.266)$ & $(0.192)$ \\
\hline
\end{tabular}

Ig a song (ref.

$\begin{array}{lcccccccc}\text { sing) } & -0.095 & 0.078 & -0.090 & -0.277^{*} & 0.141^{* *} & 0.031 & -0.048 & 0.017 \\ & (0.061) & (0.093) & (0.152) & (0.159) & (0.059) & (0.056) & (0.087) & (0.089)\end{array}$

d a story (ref.

\begin{tabular}{lcccccccc} 
story) & $0.073^{*}$ & 0.003 & 0.140 & -0.140 & -0.064 & 0.027 & 0.140 & $-0.157^{* *}$ \\
& $(0.041)$ & $(0.080)$ & $(0.112)$ & $(0.148)$ & $(0.057)$ & $(0.059)$ & $(0.093)$ & $(0.080)$ \\
\hline istant & $-0.451^{* *}$ & -0.086 & $-1.233^{* *}$ & -1.067 & $-1.215^{* * *}$ & $-1.496^{* * *}$ & $-0.829^{* *}$ & $-2.308^{* * *}$ \\
& $(0.178)$ & $(0.282)$ & $(0.580)$ & $(0.649)$ & $(0.142)$ & $(0.130)$ & $(0.382)$ & $(0.333)$
\end{tabular}

mber of

$\begin{array}{lllllll}(0.178) & (0.282) & (0.580) & (0.649) & (0.142) & (0.130) & (0.382)\end{array}$

$\begin{array}{lrrrrrrrr}\text { ervations } & 4,640 & 1,454 & 746 & 734 & 3,428 & 3,176 & 994 & 1,486\end{array}$

tes: Robust standard errors in parentheses. ${ }^{* * *} \mathrm{p}<0.01, * * \mathrm{p}<0.05, * \mathrm{p}<0.1$. Omitted/reference categories

mentioned following the "ref." abbreviation term.

Table 5: Odd Ratios (OR) for the Prevalence of Stunted Children by Country 
Costa

Chile Uruguay Rica Paraguay Mexico Salvador Nicaragua Peru

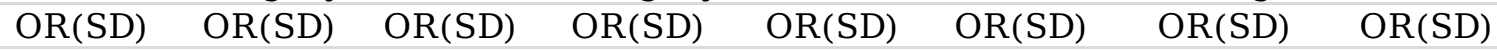

sondary (ref.

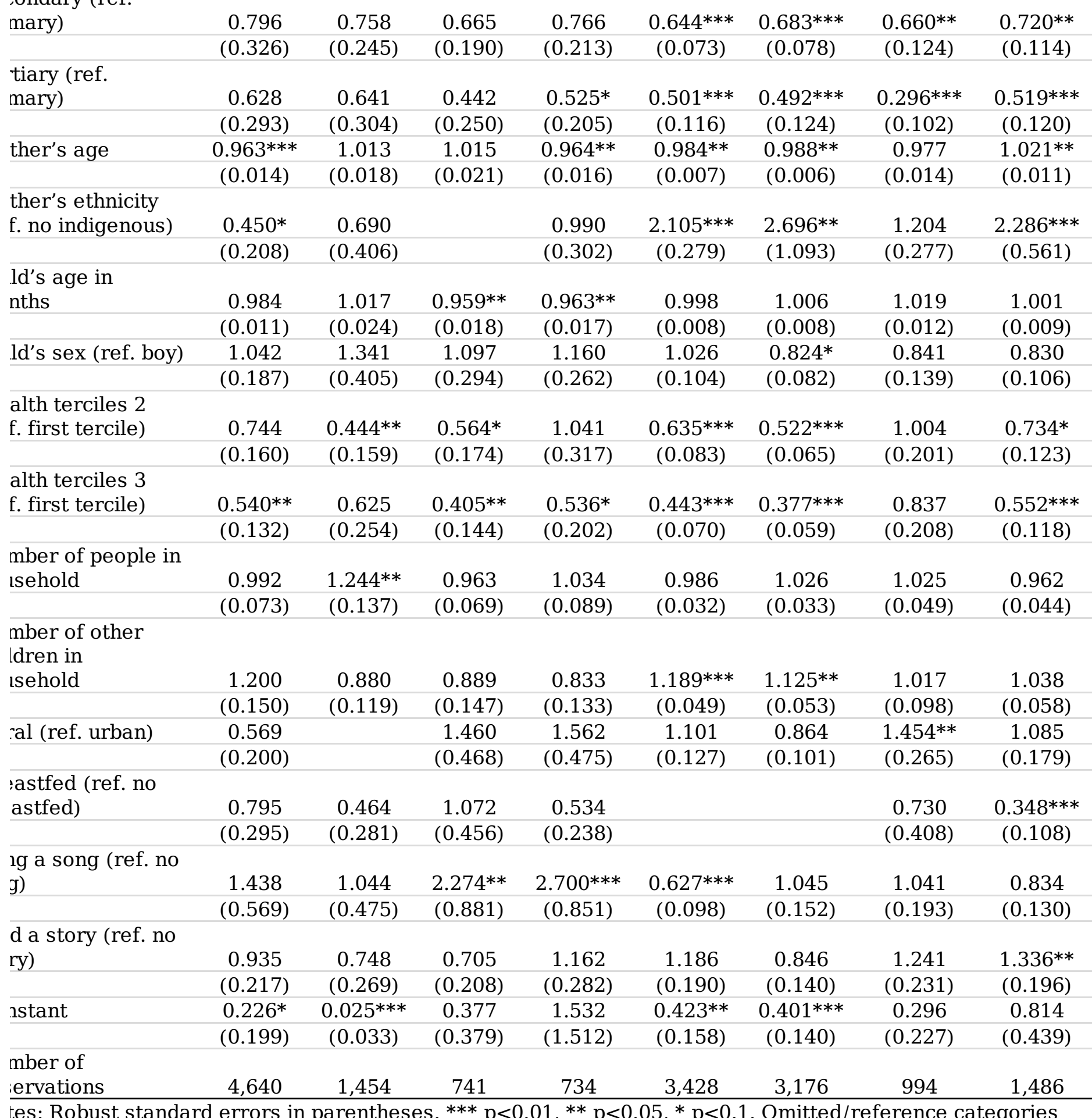

tes: Robust standard errors in parentheses. $* * * \mathrm{p}<0.01, * * \mathrm{p}<0.05, * \mathrm{p}<0.1$. Omitted/reference categories mentioned following the "ref." abbreviation term.

\section{Figures}




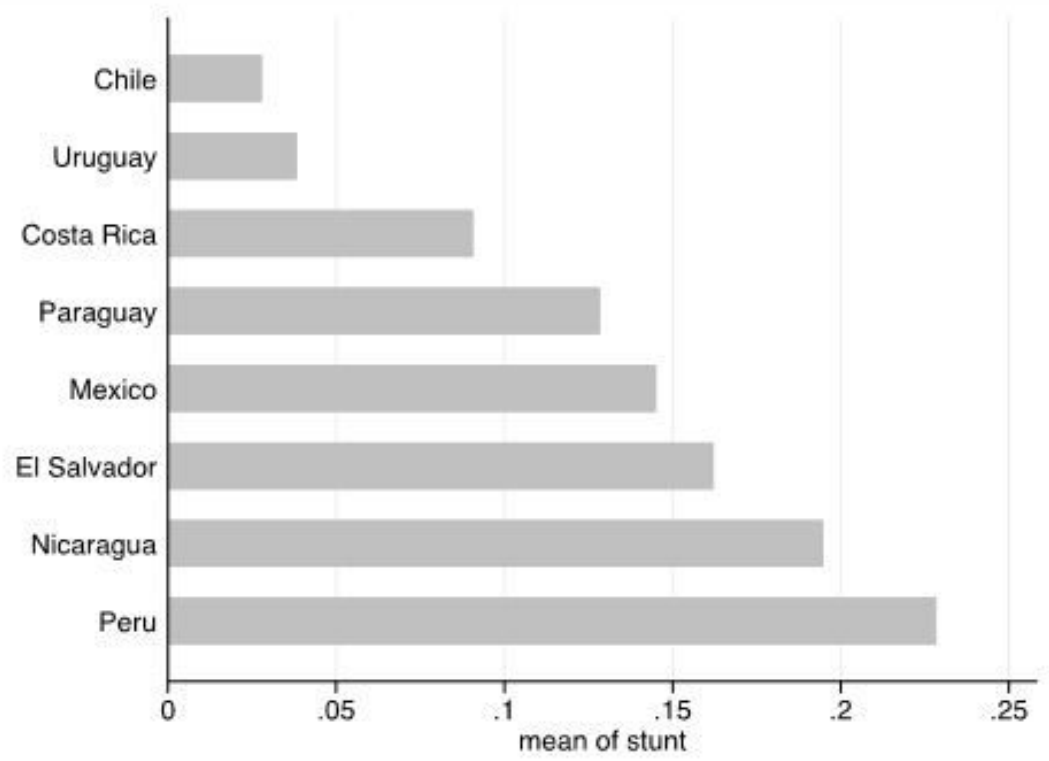

Notes: Stunting is defined as a height-for-age (z-score) less than or equal to two height-for-age standard deviations (SDs) from the WHO Child Growth Standards.

\section{Figure 1}

Prevalence of stunted children by country

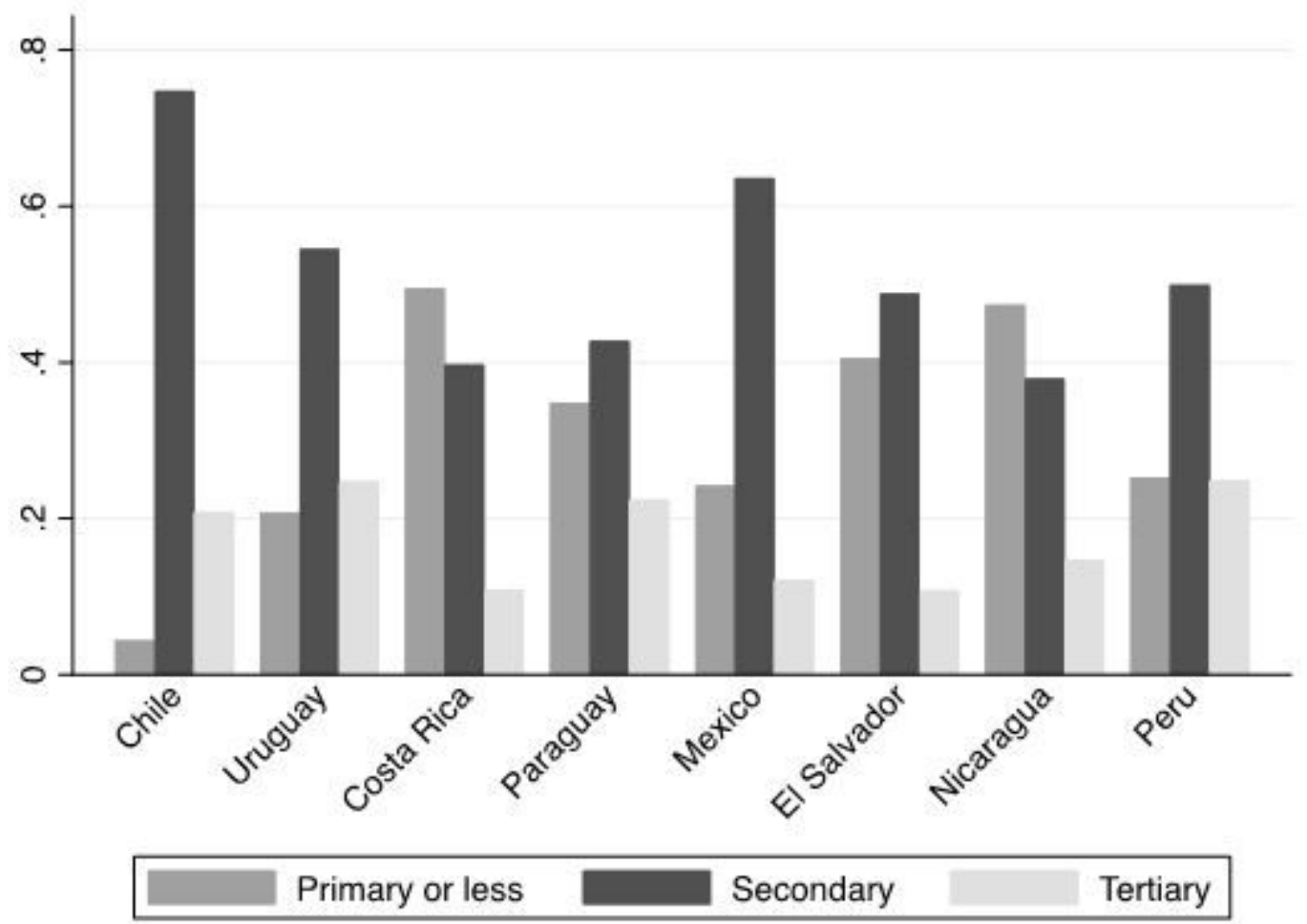

Figure 2

Maternal education level by country 


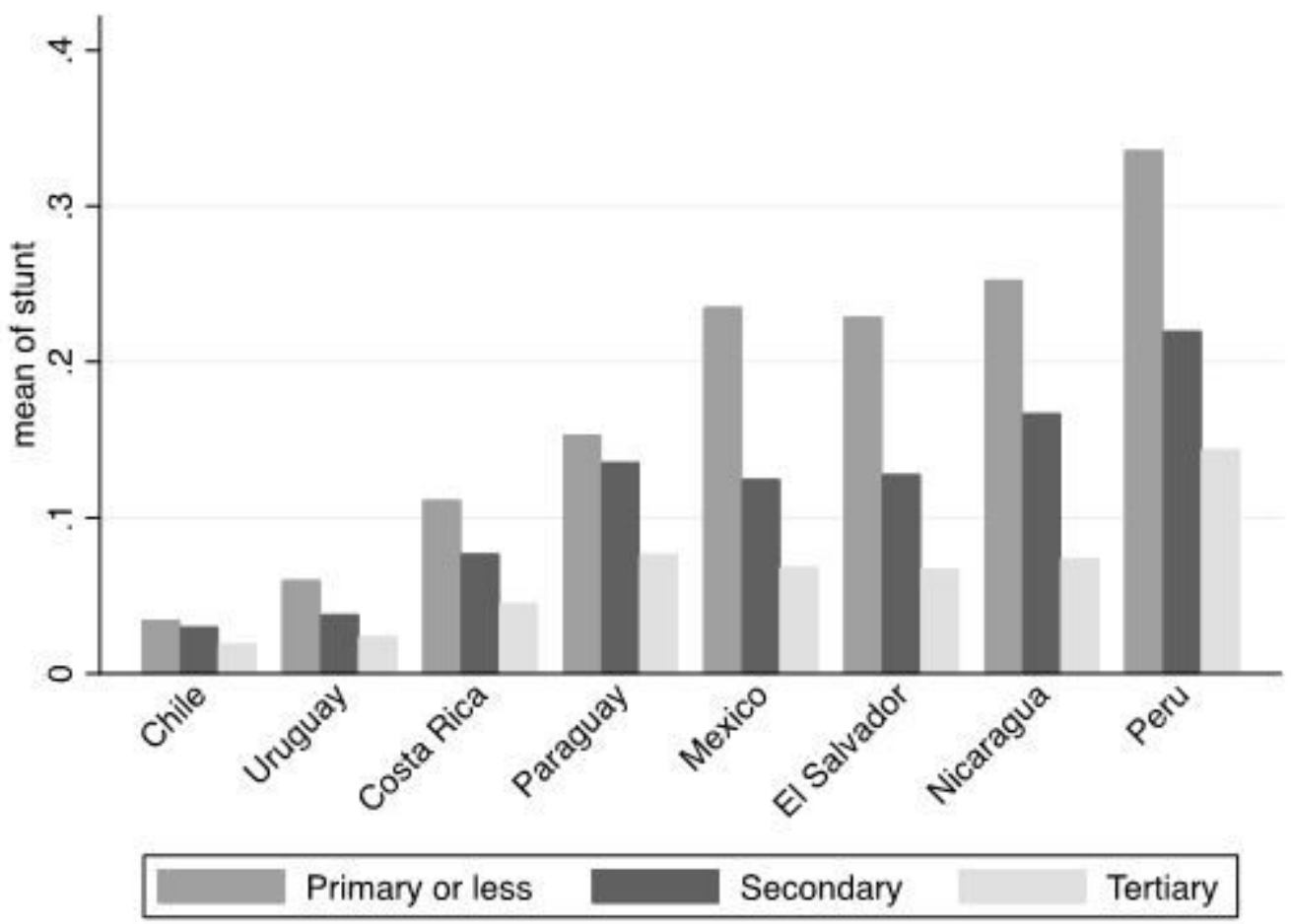

Figure 3

Children's stunting prevalence and maternal education level by country

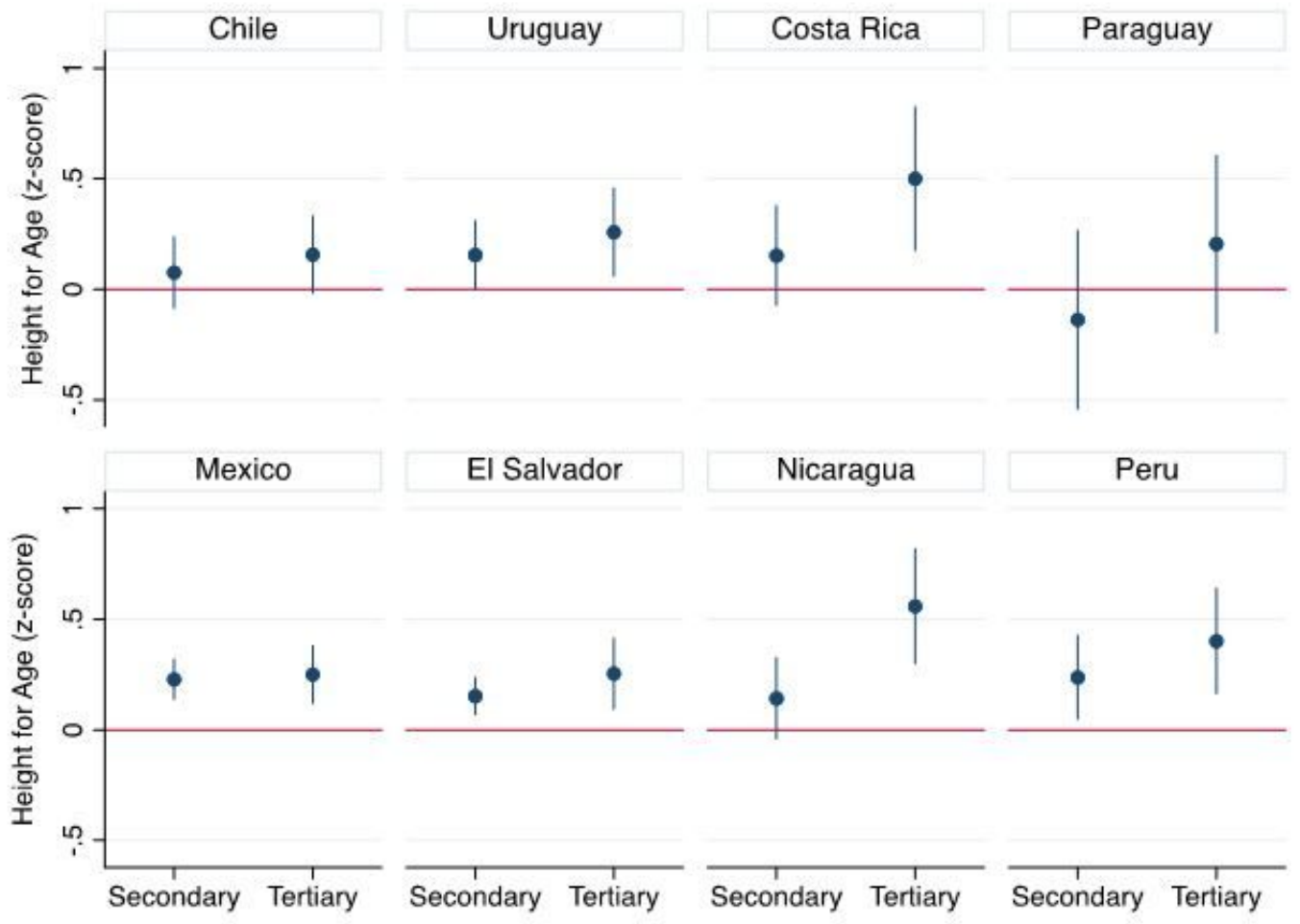

Notes: Solid dots are parameter estimates from the linear regression model detailed in Table 4 . Vertical lines are $95 \%$ confidence intervals. Red horizontal line is at zero. See Table 4 for full details. 


\section{Figure 4}

Parameter estimates for height-for-age by country from the linear regression model
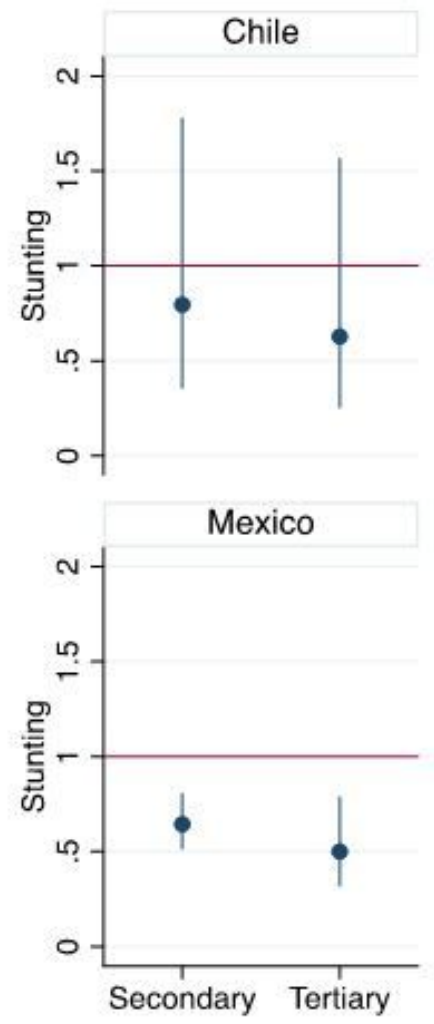

Uruguay

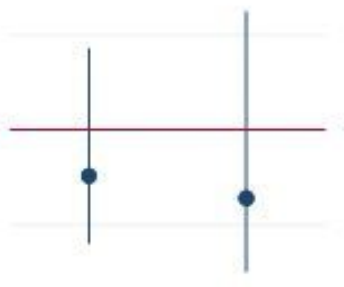

El Salvador

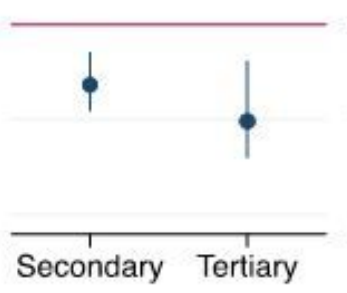

Costa Rica

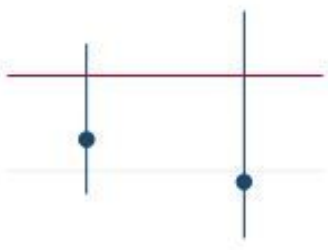

Nicaragua

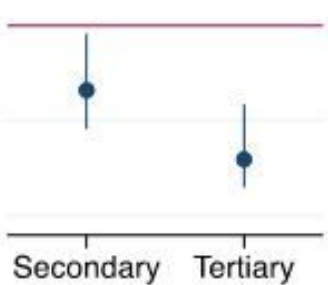

Paraguay

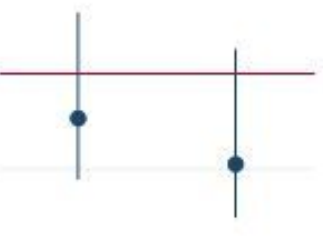

Peru

Notes: Solid dots are parameter estimates from the odds ratios detailed in Table 5 . Vertical lines are $95 \%$ confidence intervals. Red horizontal line indicates an $\mathrm{OR}=1$. $\mathrm{OR}>1$ means that education has a positive association with stunting prevalence, while $\mathrm{OR}<1$ indicates that a higher educational level tends to reduce children's stunting prevalence. See Table 5 for full models.

Figure 5

Parameter estimates for stunting prevalence by country from the odd ratios model

\section{Supplementary Files}

This is a list of supplementary files associated with this preprint. Click to download.

- formulas.docx

- 4Appendix.docx 